\title{
SISTEMATIZAÇÃO DE EXPERIÊNCIAS COMO MÉTODO PARA ELABORAR A CRÍTICA POLÍTICA
}

\section{SYSTEMATIZATION OF EXPERIENCES AS A METHOD FOR PREPARING POLITICAL CRITICISM}

\author{
Leonardo Carnut ${ }^{1}$ \\ Áquilas Mendes ${ }^{2}$ \\ Lúcia Dias da Silva Guerra ${ }^{3}$ \\ Thaís Teodoro Goraieb ${ }^{4}$ \\ Tarsila Teixeira Vilhena Lopes ${ }^{5}$
}

\begin{abstract}
Resumo: Este artigo visa discorrer sobre a relevância da Sistematização de Experiências como método que ajuda a elaborar uma crítica política aos coletivos. Para alcançar este objetivo, o texto divide-se em três seções. Uma primeira, onde se apresenta as características e fundamentos do método de Sistematização de Experiências, ressaltando seu caráter especificamente crítico-político. A segunda, na qual se abordará as questões relativas à ação, fruto da reflexão (a relação entre pensamento freireano, a luta social e a saúde) de um coletivo chamado 'Formação é Política' sediado na cidade de São Paulo - SP (Brasil). E, por fim, discorre-se sobre o uso aplicado do método ao objeto de reflexão, demonstrando como a articulação sistematizada pode proporcionar apontamentos mais claros para guiar as ações futuras do coletivo.
\end{abstract}

Palavras-chave: Sistematização de experiência; Pensamento freireano; Marxismo; Luta social; Saúde.

\begin{abstract}
This article aims to discuss the relevance of the Systematization of Experiences as a method that helps to develop a political critique of collectives. To achieve this goal, the text is divided into three sections. The first one presents the characteristics and fundamentals of the Systematization of Experiences method, emphasizing its specifically critical-political character. The second, in which the questions related to action will be addressed, as a result of the reflection (the relationship between Freire's thought, social struggle and health) of a collective called 'Formation is Politics' based in the city of São Paulo - SP (Brazil). And, finally, it discusses the applied use of the method to the object of reflection, demonstrating how the systematic articulation can provide clearer points to guide the collective's future actions.
\end{abstract}

Keywords: Systematization of experience; Freirean thinking; Marxism; Social struggle; Health.

\footnotetext{
${ }^{1}$ Pós-doutor em Saúde Pública (Ciências Sociais e Humanas em Saúde), Faculdade de Saúde Pública da Universidade de São Paulo (FSP-USP). Universidade Federal de São Paulo (UNIFESP), São Paulo, SP, Brasil. E-mail: leonardo.carnut@unifesp.br

${ }^{2}$ Doutor em Economia, Universidade Estadual de Campinas (UNICAMP). Faculdade de Saúde Pública da Universidade de São Paulo (FSP-USP), São Paulo, SP, Brasil. E-mail: aquilasmendes@ gmail.com

${ }_{3}^{3}$ Doutra em Nutrição em Saúde Pública, Faculdade de Saúde Pública da Universidade de São Paulo (FSPUSP). Faculdade Anhanguera, Campus Santana, São Paulo, SP, Brasil. E-mail: ludsguerra@ gmail.com

${ }^{4}$ Graduanda em Medicina, Faculdade de Ciências Médicas da Santa Casa de São Paulo (FCMSCSP). São Paulo, SP, Brasil. E-mail: thais.t.goraieb@gmail.com

${ }^{5}$ Doutoranda em Saúde Pública, Faculdade de Saúde Pública da Universidade de São Paulo (FSP-USP). São Paulo, SP, Brasil. E-mail: tarsilatvlopes@gmail.com
} 


\section{Introdução}

O cenário social vigente no Brasil e no mundo tem instigado a implicação dos sujeitos sociais, em suas conjunturas sociopolíticas, em deixarem suas 'marcas no mundo'. Isto tem reforçado cada vez mais os sujeitos a perceberem que as saídas para a luta política é essencialmente coletiva, e, por isso, o cenário tem proporcionado o encontro entre sujeitos com objetivos comuns relacionados à mobilização e transformação social.

Contudo, tradicionamente estes sujeitos implicados com a transformação deixam passar oportunidades importantes de aprendizado e amadurecimentos coletivos, quando não conseguem reconhecer a importância do registro e reflexão a partir dos encontros realizados. Muitas vezes induzidos por uma ação política muito pragmática (diríamos até 'ativista' em senso estrito, como dito por Freire) (FREIRE, 1996), ou até, por certo 'amadorismo' na organização de coletivos, é comum que estas potências se dissipem e gerem mais desgates do que avanços concretos. Isto reverbera em pouco aprendizado sobre a organização coletiva e quase nenhuma reflexão crítica.

Por isso, conhecer métodos de sistematizar esses encontros, podendo conjuntamente refletir sobre eles de forma regular e sistemática, favorece um acúmulo de aprendizado que é certamente muito proveitoso para o amadurecimento tanto politico quanto pedagógico sobre a realidade coletiva vivenciada. Neste sentido, o método de Sistematização de Experiências parece ser um método profícuo para ajudar coletivos, grupos, associações ou outras prospostas de agregação entre pares a refletir sobre suas práticas coletivas no intuito de criticá-las, em especial, politicamente.

A Sistematização de Experiências, por ser um método formativo, permite construir e repensar práticas cotidianas, oportunizando afirmações e críticas. $\mathrm{O}$ fato de ser também uma pesquisa participativa (produzida in acto) faz com que as pessoas, não habituadas a esta prática, possam dar-se conta da riqueza da reflexão sobre o seu cotidiano de trabalho e de suas relações. O uso da sistematização como método, colabora para a feitura de trilhas de resistência ao individualismo capitalista que fragmenta os saberes e deixa na invisibilidade práticas coletivas que necessitam ser refletidas e registradas (GALARRAGA, 2013). O método possibilita sistematizar, refletir e buscar coletivamente caminhos para o enfrentamento de realidades, conflitos e violências (TRIGOSCARRILLO, FONSECA, REINOSO, 2020; GEROMINI, 2019). 
É neste caminho que este artigo visa discorrer sobre a relevância da Sistematização de Experiências como método que ajuda a elaborar uma crítica política aos coletivos. Defende-se aqui, através do exemplo concreto de um coletivo de formação política, que a sistematização pode ajudar a refletir a prática de ação formativa a ponto de ser o registro necessário que orienta a transformação desta prática a fim de qualificá-la.

Para alcançar este objetivo, o texto divide-se em três seções. Uma primeira, onde se apresenta as características e fundamentos do método de Sistematização de Experiências, ressaltando seu caráter especificamente crítico-político. A segunda, na qual se abordará as questões relativas à ação, fruto da reflexão (a relação entre pensamento freireano, luta social e a saúde) de um coletivo chamado 'Formação é Política' sediado na cidade de São Paulo - SP (Brasil). E, por fim, se discorrerá sobre o uso aplicado do método ao objeto de reflexão, demonstrando como a articulação sistematizada pode proporcionar apontamentos mais claros para donde guiar as ações futuras do coletivo.

\section{O que é 'Sistematização'? E que tipo de 'Experiência'?}

Ao rigor vernáculo, o termo 'sistematização' significa organizar (diversos elementos) em um sistema ou ainda sintetizar um conjunto de fatos, ideias, opniões e conceitos a luz de uma doutrina. Talvez, foi pensando neste último significado que o termo 'sistematização' pode relacionar-se à intencionalidade (ou, sobretudo, à ética entendida como a política) de um grupo ${ }^{6}$ (BOBBIO, 2016).

Não obstante, Chavez-Tafur (2007) vai utilizar o termo 'sistematização' como um processo que procura organizar as informações resultantes de um determinado projeto de campo. Visa analisá-las de forma minuciosa e aprender lições a partir delas (CHAVEZTAFUR, 2007), sendo esta característica, o objetivo central deste método. De uma maneira resumida poder-se-ia dizer que 'sistematizar' possibilita uma compreensão mais aprofundada das experiências que se realiza nos cotidianos grupais, com a finalidade de melhorar a própria prática coletiva (SIMON, 2007).

Contudo, quando se fala em sistematização como um método de apreensãocompreensão de uma realidade se deve pensar no ato de 'sistematizar' de forma rigorosa. Isso exige considerar que a sistematização deve ser encarada enquanto (1) um evento que precede a prática, (2) que reconhece o sujeito partícipe com produtor de conhecimento,

\footnotetext{
${ }^{6}$ Nestes termos há um borramento entre os conceitos de ética e política. Para Bobbio, a política é considerada como 'ética de um grupo' quando ela se refere a 'ética da responsabilidade' de um líder sobre o interesse do grupo em determinada ação. Para maiores esclarecimentos ver Bobbio (2016, p. 961).
} 
(3) que se trata sempre de um processo de interlocução, (4) que não é um processo neutro, e sim guiado por valores que visam emancipar os sujeitos partícipes, como também transformar uma realidade que lhes é comum, (5) e que, ao sistematizar, interessa ao grupo tanto o processo quanto o produto desta sistematização, ou seja, ambos têm o mesmo valor (KUBO, 2009).

Assim, pode-se admitir que o poder do método não reside apenas nas lições e aprendizados que ele gera, mas essencialmente no papel em que os sujeitos detêm em fazer conhecimento a partir de suas interações. A rigor, a 'sistematização' é dada em (re)organizar metodicamente algo, e este 'algo' também é o conhecimento de si próprio. Portanto, este 'algo' se refere a experiências práticas concretas, experiências vitais carregadas de uma enorme riqueza acumulada que move e remove os sujeitos implicandoos na vida. São estes os elementos, os valores e as crenças que em cada caso tornam os processos inéditos e irrepetíveis (SIMON, 2007).

Portanto, é uma operação de reconstrução e reflexão para interpretar o sucedido e compreendê-lo única(coletiva)mente. É um esforço intencional para a construção da consciência do que se busca e clareza das possibilidades 'único-coletivas' e limites da prática sobre o que foi sistematizado (FRAGA et al., 2015). Contudo é pertinente atentar que o processo de sistematização não é um processo de 'avaliação de resultados' ou de ‘impacto das experiências' estudadas. O foco da ação é a descrição das experiências, suas transversalidades, reflexões e recomendações cujo processo de aproximação permitiu e/ou suscitou (FERNANDES; EDMUNDO; DADACH, 2009).

Já quando falamos sobre 'experiências' se pensa primeiramente sobre qualquer conhecimento obtido por meio dos sentidos. A experiência sensível (ou seja, por meio dos cinco sentidos) abre, de certo, o caminho para experiência, contudo não está (e nem deve estar) restrita ao físico. A experiência (sensível), como furto do 'experimento' reduz o 'experienciar' ao 'experimentar'. Quando se fala de 'experiências' como objeto de sistematização neste método se refere ao 'experenciar', ou seja, a experiência para além de sua sensibilidade física, envolvendo em si todas as afetações próprias da construção de sentimentos e, claro, as emoções sobre o vivido.

Reafirmando o experienciar como algo essencialmente humano, carregado da complexidade de elementos possíveis de serem criados e recriados a partir de cada momento vivido, de apreender e aprender que tem em si uma mescla de processos e implicações para além do físico, é que se justifica o 'experenciar' para além dos aspectos puramente biológicos. Trata-se do que Cansi (2020) demonstra criticamente em sua 
experiência de educação e arte, possibilitando conhecermos a 'educação sensível' e elaborarmos a compreensão de que a experiência 'passa pelo corpo' (para além das sensações e sentidos).

Por isso, as experiências neste método são processos complexos onde intervêm uma série de fatores objetivos e, especialmente subjetivos que se interligam, dentre eles: a) as condições de contexto ou de momento histórico em que se desenvolvem; b) as situações particulares que as tornaram possíveis; c) as ações intencionais que são realizadas com determinados objetivos (ou ações não-intencionais que são apenas respostas a situações); d) as reações geradas a partir das ações; e) os resultados esperados ou não-esperados que vão surgindo; f) as percepções, interpretações, intuições e emoções dos homens e das mulheres intervenientes; e, g) as relações que se estabelecem entre os sujeitos das experiências (HOLLIDAY, 2008).

Assim, quando se considera uma experiência para sistematizá-la, manter-se atenta(o) a todos esses elementos que garantem o 'caldo cultural' da experiência demonstra-se mais importante que materialidade da experiência em si. Isto se torna particulamente difícil quando o objeto da sistematização (ou seja, a experiência a ser sistematizada) é uma atividade donde há necessidade de se reconhecer, assumir e vivenciar novos valores (CURADO; SANTOS; OLIVEIRA, 2014). Essa mudança qualitativa, tão sui generis deste processo, encontra obstáculos quando estas necessidades se concentram no relativizar 'o político' que está dentro de cada um.

Não por acaso, muitos coletivos políticos ainda despendem poucos esforços no processo de sistematização. A diversidade e intensidade das tarefas no campo de lutas são tão intensas e os fatores alegados são inúmeros que, de certa forma, gera uma limitada dedicação destes grupos às ações de sistematização/reflexão de suas próprias atividades. De uma forma geral, esta 'falta de tempo' passa a ser encarada como um obstáculo, e não como uma resistência a necessidade de se relativizar (CHAVEZ-TAFUR, 2007). É neste contexto em que o uso da Sistematização de Experiências para organização de coletivos e movimentos sociais parece interessante. Ao passo em que expõe com firmeza a propensão dos sujeitos a repensarem politicamente seus atos, valores e assunções, dialeticamente serve de aprendizado para reafirmá-los ou refutá-los, podendo recriar arranjos outrora considerados inimagináveis, inconsebíveis, para organização e luta coletiva.

Carneiro (2011) aponta cinco objetivos em que o método pode ser útil para grupos populares, organizações políticas ou assemelhados. São estes: 1) contribuir na 
organização popular para conquista de novos direitos e efetivação daqueles já garantidos legalmente; 2) elevar a autoestima, autonomia e ampliar o protagonismo dos sujeitos envolvidos; 3) contribuir na criação de novas formas de sociabilidade, fundadas no afeto, na democracia participativa, solidariedade e autogestão; 4) melhorar as condições materiais de vida das pessoas envolvidas; 5) investir na formação, para melhor compreensão do funcionamento da sociedade, e assim poder transformá-la.

Neste sentido, os grupos que se permitem experenciar o método, além do enfoque científico que podem obter sobre suas práticas, tendem a se sentirem mais 'permitidos' ao debate público sobre 'o conhecimento' em condições de igualdade com o 'saber univeristário' pois o método pode fomentar a crítica ao próprio poder da ciência no desenvolvimento da sociedade de forma mais clara, realçando o caráter eminentemente político que há por trás das opções técnicas/tecnólogicas, metodológicas, e sem esquecer das ontoepistemológicas (CURADO; SANTOS; OLIVEIRA, 2014).

É daí que emerge, como aponta Rodríguez (2016), o caráter político deste método. Ele recupera sua importância para grupos/movimentos/coletivos a luz da (re)elaboração da crítica política sobre as experiências em sistematização destes grupos, pois é a partir da produção de conhecimento como uma produção política que se desenvolve o empoderamento dos sujeitos nelas implicados. Portanto, é pelo desvelar as ideologias atuais e/ou por entender sua realidade para transformá-la que a produção política do conhecimento se mobiliza, mobilizando sentidos e significados sobre o sujeito cognoscente, sobre as epistemologias de onde ocorre, sobre os métodos de produção, sobre a própria natureza do conhecimento e, finalmente, a natureza da realidade.

Por isso a sistematização de experiências visa a produção de um conhecimento próprio, único, localmente situado e contextualizado a luz da intencionalidade política dos sujeitos producentes desta sistematização. Em outras palavras, trata-se de um método que radicaliza a crítica à produção de conhecimento de matriz eurocêntrica, fortemente influenciada pelo positivismo que estabeleceu um discurso político sobre o 'conhecer a realidade' que é sobreposta às formas socialmente válidas do viver periférico, dependente, em suma, latinoamericano (RODRÍGUEZ, 2016). Esta lógica de produção do conhecimento de matriz eurocêntrica é comumente encontrada nas sistematizações de experiências na literatura científica da área da saúde quando seus autores não se apropriam adequadamente da discussão epistemológica sobre método (GOYENECHE, PLATA, GARCÍA, 2020; GONZÁLEZ, 2019). 
Para ilustrar empiricamente, em consonância com a argumentação apresentada, irse-á demonstrar como um grupo de militantes/trabalhadores chamado 'Coletivo Formação é Política', sediado em São Paulo - SP (Brasil), se utiliza do método de sistematização de sua experiência para formentar a crítica política de suas ações. Iniciarse-á, então pela exposição do objeto de sistematização: a articulação entre 'pensamento freireano, luta social e saúde', considerado necessário para a compreensão da tarefa de formação política do coletivo.

\section{Objeto da Sistematização de uma Experiência: a articulação entre 'pensamento freireano, luta social e saúde'}

Neste momento, para o coletivo era essencial compreender o objeto de sua sistematização. Assim, as relações entre 'pensamento freireano-luta-saúde' perpassam razões que encontram origem no estranhamento do conhecimento produzido nas universidades e nos questionamentos a respeito do reducionismo do ensino em saúde que artificialmente produzem e desarticulam estes dois elementos em relação à luta social.

Neste sentido, se reconhece que nas universidades em todo o mundo, por mais avanços que tenham acontecido no processo de ensino-aprendizagem para 'alargar' as dimensões do trabalho em saúde (CARVALHO; CECIM, 2006), pouco se avançou concretamente na 'reconexão' da prática sanitária aos marcos do modo de produção capitalista, arrefecendo, gradualmente, a orientação necessária em direção à crítica do capitalismo e sua essência (CARNUT et al., 2017).

Portanto, concorda-se com Tragtenberg (2007), quando, em sua ácida crítica aos redutos da universidade no Brasil, ressalta seu caráter classista e 'aburguesado', tanto do ponto de vista do corpo docente quanto dos estudantes que ali se encontram. Claro que, mesmo diante dos diversos avanços na 'popularização' da universidade pública no Brasil (MOREIRA et al., 2017) ainda há muito para se popularizar, por isso esperar da universidade algum tipo de educação política para os trabalhadores que dali se formam é, em última instância, uma ingenuidade pueril. Isto é possível identificar em sistematizações de experiências na área da saúde em que apresentação das pesquisas e os usos dos instrumentos buscam mais aumentar a assertividade/refutabilidade das intervenções (FERREIRA et al., 2020; OLIVEIRA et al., 2019) do que politizá-las.

Neste sentido, uma pedagogia mais crítica, alinhada à emancipação da classe trabalhadora dificilmente irá advir de um contexto universitário (MARIÁTEGUI, 1975), 
especialmente no âmbito da saúde. Os cursos de saúde, quando apresentam alguma inclinação ao 'social' (ABRASCO, 2019), majoritariamente se restringem ao marcos do pós-modernismo (SCHWARTZ, 2002), reafirmando os valores identitários, familiares e comunitários e refutando sistematicamente a centralidade do trabalho nas discussões que, forçosamente, levariam à crítica do modo de se produzir 'saúde' de forma totalizante.

Assim, espera-se que uma pedagogia que instigue para a luta social seja o modo de trabalho de 'coletivos organizados', movimento sociais outras formas de ação coletiva, cuja educação não-formal seja a prática de liberdade necessária para uma pedagogia crítica realmente emancipadora. Portanto, ao problematizarmos a luta social na saúde, é essencial compreender que o marco das Pedagogias Críticas deve ser a base teóricometodológica nestes processos de ensino-aprendizagem.

As lutas sociais pela saúde são cotidianas e datam, na história recente, desde a criação do Sistema Único de Saúde (SUS) no país (BRAVO, 2011). Entre momentos de acirramento e calmarias, a militância implicada na defesa do direito à saúde sempre esteve presente durante estes 30 anos do sistema. Contudo, nos últimos três anos (desde o 'prégolpe institucional de 2016' no Brasil) (JINKINGS; DORIA; CLETO, 2016), o engajamento de novos sujeitos e a mobilização popular para além dos partidos têm sido a marca deste período sócio-histórico em que vivemos.

Neste sentido, a formação de novos coletivos pelo direito à saúde adentra a cena sócio-política e se utilizam da prática pedagógica com instrumento de luta. Essa forma de ação/militância política é o que podemos chamar, em grande medida, como 'educação política' e o que interessa na experiência do coletivo em tela.

A educação política, como toda categoria, é plural e diversa e encontra-se operacionalizada de diversas formas. Por ter como objetivo a 'forjar politicamente' um sujeito pode ter como intencionalidade quaisquer viéses ideológicos, inclusive, como reportado por Marx e Engels (2007), aquele próprio dos interesses da burguesia.

Em termos práxicos, podemos dividir a educação política em duas grandes perspectivas: a 'política na formação' e a 'formação política'. A 'política na formação' está relacionada com a inserção dos conteúdos sobre política (em sentido lato) nos conteúdos essenciais dos cursos de graduação. Essa aposta da educação política tem na educação formal seu lócus de ação concreta. Na atividade universitária, o espaço deste tipo de educação política cada vez mais tem se restringido às atividades de extensão universitária ou extraclasses, limitando-se a raros momentos de estudos dirigidos ou às atividades de menor prestígio acadêmico. 
Já a 'formação política' é o ato educativo de formação de quadros de liderança entre os alunos, trabalhadores e outros segmentos para organização dos assuntos de interesse de sua categoria. Não raro, os membros de determinado segmento social que recebem 'formação política' assumem grêmios, diretórios acadêmicos (MOURA, 2010), entidades profissionais e representações de outras ordens dentro no mundo universitário e fora dele, alcançando posições de destaque, arregimentando a luta e, consequentemente, direcionando a decisão.

Tradicionalmente este tipo de formação detém conteúdos a respeito da conjuntura política nacional/internacional, sobre os fundamentos do capitalismo e sobre o papel da luta/assistência estudantil no mundo universitário (CRUZ, 1994). Mesmo reconhecendo a relevância desta proposta, este tipo de formação corre paralela (ou à margem) aos conteúdos essenciais dos cursos de graduação. Assim, é a esse tipo de educação política em que vamos nos deter neste relato.

Compreendemos que para forjar politicamente um trabalhador ou estudante genuinamente crítico no setor saúde, tomar como base pedagógica as teorias críticas é essencial. Desde 1997, vem se firmando no meio educacional em saúde a "pedagogia libertadora" (FREIRE, 1996) e a "pedagogia crítico-social dos conteúdos", defendidas por educadores de orientação marxista (PEREIRA, 2003). Decidimos, por uma questão de recorte analítico, focalizar nossa atenção para a pedagogia libertadora freireana por acreditar que esta é a mais difundida no setor saúde e ainda tem como base a participação como fundamento pedagógico chave.

Diante deste cenário, é que em 2017 foi formado um coletivo chamado 'Formação é Política', no estado de São Paulo, Brasil, realizado na Associação Paulista de Saúde Pública (APSP) que congrega professores e trabalhadores da área da saúde com o intuito de organizar um processo de trabalho de base (PELOSO, 2012) cuja orientação é a formação política crítica marxista da classe trabalhadora neste setor.

Para concretizar essa tarefa, a opção pedagógica era fundamental. Assim, escolheu-se trabalhar com pedagogias críticas, especificamente, com métodos ativos de ensino-aprendizagem derivado do pensamento freireano e suas premissas fundamentais. Neste sentido, um grupo de leitura em 'Pedagogias Críticas e Saúde' foi criado dentro deste coletivo 'Formação é Política' para refletir sobre este trabalho de base e para estranhar a lógica de produção de conhecimento no capitalismo, cuja lógica encontra na educação tradicional terreno fértil para sua reprodução. Esta sistematização teve como 
primeiro passo a publicação realizada por Carnut et al., (2019) no $8^{\circ}$. Congresso Iberoamericano de Investigação Qualitativa, ocorrido em Lisboa, Portugal, 2019.

\section{Usando a Sistematizção de Experiência em um caso concreto: o Amadurecimento Pedagógico para uma prática de Formação Política}

É essencial salientar que a metodologia de sistematização de experiências é um método proposto por Oscar Jara Holliday (2006), cuja orientação epistêmica se encontra fundamentada na concepção metodológica dialética. Este método foi escolhido pelo fato das pesquisas sociais qualitativas que visam produzir conhecimento de forma democrática e coletiva dever levar em consideração que a prática de pesquisa necessita ser 'com' os seres humanos, e não 'em' seres humanos, e por isso, a sistematização de experiência pode ser um importante método neste caminho.

Segundo Altamira e Canarias (2003), a concepção metodológica dialética é uma maneira de conceber a realidade, de aproximar-se dela para conhecê-la e de atuar sobre ela para transformá-la. É, por isso, uma maneira integral de pensar e de viver: uma filosofia.

A sistematização de experiências no campo da educação apresenta algumas vantagens que dialogam com a ideia de melhorar as práticas, ou seja, no sentido de mudança em geral, seja de forma individual ou coletiva. A sistematização instiga os sujeitos a adquirem ao longo deste percurso o hábito reflexivo sobre suas ações, assim como gerar práticas mais conscientes a partir da leitura crítica da realidade.

Do ponto de vista coletivo, a proposta da sistematização gera intercâmbio de aprendizagens, pois com o uso dos registros, que podem ser feitos em diversas linguagens tais como anotações, imagens, vídeos, etc, tem-se as condições de organizar as informações, as percepções e as avaliações das experiências vividas de forma a trocá-las com outras pessoas ou grupos.

Além destes elementos, sistematizar experiências contribui com o enriquecimento, amadurecimento e análise de alguma teoria, pois os registros realizados sobre uma experiência vivenciada também são fontes empíricas sobre os fatos observados (e por múltiplos 'viventes'), que podem colaborar na validação de afirmações teóricas apresentadas ou criar argumentos que as questionem. Rodríguez-Sosa et al., (2019) colabora nesta direção, ao interpretar criticamente a experiência do processo pedagógico, buscando aprender com ela e melhorar as práticas futuras; e questionando as próprias 
crenças e práticas do grupo analisado, para alcançar habilidades críticas e problematizadoras.

O que mais interessa nesta reflexão é a característica ímpar que este método possui em gerar 'incidência política' sobre os sujeitos, pois a sistematização das vivências que fundamentam as pautas de lutas dos movimentos sociais, por exemplo, também podem ser fontes de informação legítimas da realidade que se deseja transformar e, por conseguinte, de suas reivindicações. Por isso, compreende-se a potência deste método como forma de fortalecer a identidade de grupos, pois a sistematização possibilita a capacidade de gerar uma percepção apurada dos diversos aspectos que formam a composição de grupos, delineando seu perfil, sua identidade e alinhando-a taticamente à luta.

Considerando todos estes elementos é que este artigo traz o relato de experiência sobre os estudos pedagógicos a respeito da pedagogia da autonomia de Paulo Freire em seu nascedouro e desenvolvimento. O grupo de leitura 'Pedagogias Críticas e Saúde' teve a participação dos organizadores do coletivo 'Formação é Política' no intuito de instigar a reflexão e formação pedagógica necessária para este trabalho de base.

\subsection{Os Participantes}

O grupo de leitura em 'Pedagogias Críticas e Saúde' teve a participação 12 trabalhadores com ensino superior completo, professores (mestres, doutores e pósdoutores) e estudantes de graduação e pós-graduação (mestrado e doutorado) das diversas áreas da saúde (ex.: medicina, odontologia, farmácia, enfermagem) que além da sua formação e atuação cotidiana, atuam também como moderadores e facilitadores do 'Coletivo Formação é Política'. Este coletivo de trabalhadores reunia-se uma vez ao mês durante todo o ano de 2018, no Centro de Desenvolvimento do Ensino Superior em Saúde (CEDESS) da Universidade Federal de São Paulo, para realizarem o processo de leitura e formação no intuito de instigar a reflexão e formação pedagógica necessária para este trabalho de base (PELOSO, 2012).

\subsection{Os Fundamentos Teóricos-Pedagógicos}

Metodologicamente, o grupo de leitura se organizou através do método da roda apostando em seu potencial pedagógico conforme apontado por D’Ascenzi e Lima (2013). Estes autores explicitam que este método ajuda na presença de educação 
continuada a partir da socialização do conhecimento dos diversos segmentos. Neste caso, as seções eram orientadas através da leitura prévia do texto e leitura coletiva de destaques do grupo a respeito daquele elemento essencial do pensamento freireano que ajuda a qualificar a prática pedagógica no curso de formação política.

Assim, uma primeira agenda de leituras foi cumprida na qual foram lidos os autores Paulo Freire, Marilda Behrens e Maurício Tragtenberg com os seguintes textos (Tabela 1).

Para fins analíticos, optou-se neste trabalho relatar apenas as contribuições da pedagogia da autonomia de Paulo Freire (Texto 1) para reflexão conjunta do coletivo sobre a prática da educação política em uma perspectiva libertadora.

Tabela 1: Autores e textos lidos nas leituras sobre Pedagogias Críticas e Saúde pelo coletivo Curso de Formação Política em Saúde. Março-Junho, 2018.

\begin{tabular}{|c|c|c|}
\hline Ordem dos Textos & Referência Utilizada & Nível de Reflexão e Crítica \\
\hline Texto 1 & $\begin{array}{l}\text { FREIRE, Paulo. Virtudes do educador. Verede - Centro de Estudos } \\
\text { em Educação. } 1985\end{array}$ & $\begin{array}{l}\text { Sobre o encontro educador- } \\
\text { educando }\end{array}$ \\
\hline Texto 2 & $\begin{array}{l}\text { FREIRE, Paulo. Capítulo 1: Não há docência sem discência. In: } \\
\text { Pedagogia da autonomia - Saberes necessários à prática educativa. } \\
\text { 1996, pp. } 21-45 \text {. }\end{array}$ & $\begin{array}{l}\text { Sobre o encontro educador- } \\
\text { educando }\end{array}$ \\
\hline Texto 3 & $\begin{array}{l}\text { BEHRENS, Marilda Aparecida. Paradigmas conservadores - a } \\
\text { reprodução do conhecimento. In: } \\
\text { prática pedagógica. p. } 39-52.1999 .\end{array}$ & $\begin{array}{l}\text { Sobre os paradigmas } \\
\text { educacionais }\end{array}$ \\
\hline Texto 4 & $\begin{array}{l}\text { BEHRENS, Marilda Aparecida. Paradigmas inovadores }- \text { a } \\
\text { produção do conhecimento. In: } \ldots \text {. O paradigma emergente e a } \\
\text { prática pedagógica. p. } 53-91.1999 .\end{array}$ & $\begin{array}{l}\text { Sobre os paradigmas } \\
\text { educacionais }\end{array}$ \\
\hline Texto 5 & $\begin{array}{l}\text { TRAGTENBERG, Maurício. A delinquência acadêmica. In: } \\
\text { Sobre educação, política e sindicalismo. } 3 \text { a. ed. São Paulo: Editora } \\
\text { Unesp, } 2004 \text {. }\end{array}$ & $\begin{array}{l}\text { Sobre o lugar classista da } \\
\text { universidade e a necessidade } \\
\text { da educação popular }\end{array}$ \\
\hline
\end{tabular}

Fonte: Próprios autores

Em termos de sistematização das leituras, foi utilizado o método de Sistematização de Experiência descrito por Holliday (2006) tendo como dado estes destaques no texto e anotações da discussão do grupo. O objetivo foi organizar as práticas populares para que não se 'perca o foco' e ajudar a avançar no alcance do(s) interesse(s) do grupo. Cinco momentos compuseram esta sistematização: o ponto de partida, as perguntas iniciais, a recuperação do processo vivido, a reflexão de fundo e os pontos de chegada.

\subsection{Relatando a experiência: um encontro práxico da 'do-discência'7}

\footnotetext{
${ }^{7}$ Neste texto foi abordada apenas a sistematização da experiência com o Texto 1 de Paulo Freire para título de apresentação do método. A sistematização completa do pensamento freireano feita pelo coletivo (que evolve o Texto 2 de Paulo Freire) encontra-se publicado na íntegra no artigo "Educação política e pensamento freireano: sistematizando o diálogo entre luta social e saúde" na Revista Educación, Política y Sociedad, 2020.
} 
Partiu-se do fato de que o encontro proporcionado pelo grupo é um potente espaço para o processo formativo participativo. Por isso, o "estudar juntos" é essencial na formação política pois expande a capacidade intelectual e ajuda a relembrar momentos de ensino-aprendizagem que dialogam com conteúdo do texto, e que porventura, possa fazer sentido para uns e não para outros integrantes do grupo.

Foi neste (com)partilhar que as perguntas iniciais que guiaram a leitura da pedagogia freireana foram estabelecidas: 'o que Freire nos ilumina sobre o processo pedagógico da formação política que estamos vivenciando?', 'Quais pontos são essenciais?' e 'Como eles podem nos ajudar a melhorar nossa prática como profissionais e educadores da saúde?' e "Como fazer para proporcionar a curiosidade e o pennsamento crítico na classe trabalhadora"?

Assim, em conjunto com a recuperação dos momentos vivenciados na formação política, vários fragmentos de texto foram identificados como ensinamentos que Freire aponta e que amadurece o pensamento pedagógico sobre o processo formativo em questão. Estes fragmentos do texto, identificado por todos dos membros do grupo como essenciais, tornaram-se os dados empíricos que instigaram a elaboração da crítica sobre como orientar a prática pedagógica para luta social no setor saúde.

Na leitura de 'Virtudes do Educador', um dos textos fundacionais do pensamento freireano, o grupo destacou que as virtudes são atitudes a se construir e não devem ser compreendidas como uma naturalização, ou seja, não se deve vê-las como um 'dom'. As virtudes do educador criam-se no ato de educar reflexivo, portanto é processo social em ato e não estão restritas ao indivíduo, conforme aponta o autor:

estas virtudes não podem ser vistas como algo com o qual algumas pessoas nascem ou um presente que uns recebem, mas como uma forma de ser, de encarar, de comportar-se, de compreender, tudo o que se cria através da prática, na busca de transformação da sociedade. Não são qualidade abstratas, que existem independentes de nós, ao contrário, que se criam conosco (e não individualmente) (FREIRE, 1985, p. 1).

Neste sentido, são estas as virtudes de um educador comprometido com uma transformação da sociedade na tentativa de torná-la para menos injusta. Este elemento do pensamento freireano dialoga fortemente com o propósito do curso. Assim, o exercício das virtudes anda em consonância com o processo de educação política crítica, já que o elemento do compromisso com a mudança e com a justiça social é condição em comum esta formação. Conforme aponta Freire: "não são virtudes de qualquer educador mas daqueles que estão comprometidos com a transformação da sociedade injusta e na criação de uma sociedade menos injusta" (FREIRE, 1985, p. 1). 
Assim, o grupo entende que é obrigação de quem se dedica à formação política crítica diminuir a distância entre discurso e prática. Este é um pré-requisito fundamental na luta política. Neste ponto Freire assevera a: "necessidade de diminuir a distância entre o discurso e a prática. [...] No nível da luta política, digo que é preciso diminuir a distância entre o discurso do candidato e a prática do eleito, de tal maneira que em algum momento a prática seja discurso e o discurso seja prática" (FREIRE, 1985, p. 1).

Este processo requer também a percepção do aluno sobre a formação que está sendo construído. Em um intenso processo de retroalimentação, só é possível dizer que a criticidade está sendo construída, quando o próprio formador também é objeto da crítica. Assim, Freire nos relembra que é importante para a prática pedagógica a crítica sobre ela própria e a quem a conduz: "mas eu não posso proclamar minha opção por uma sociedade mais justa, participativa e, ao mesmo tempo, desprezar um aluno que faz crítica de mim enquanto professor" (FREIRE, 1985, p. 2).

E é neste terreno em que um dos binômios freireanos emerge com muita intensidade e nos faz refletir sobre a formação política realizada, especialmente por se tratar de trabalhadores na área da saúde. Devido ao pouco contato com o método pedagógico participativo e com o conteúdo sobe teoria política marxista, a tensão proporcionada pelo conteúdo tende a 'calar' o trabalhador. Ao mesmo tempo, o educador precisa compreender os motivos dos silêncios que ali se instalam respeitando o tempo pedagógico de cada um. Neste aspecto: "se trata de trabalhar a tensão permanente que se cria entre a palavra do educador e o silêncio do educando, entre a palavra dos educandos e o silêncio do educador. [...] se não sei escutar os educandos e não me exponho à palavra deles, termino discursando "para" eles" (FREIRE, 1985, p. 2).

Assim, através das 'palavras-e-silêncios' pedagógicos, o processo ensinoaprendizagem se conforma em sentido oposto ao tradicional. Deixa de ser uma pedagogia de respostas prontas, padronizadas e fixas, para ser uma pedagogia da pergunta, que para o grupo, é essencial para elaboração da crítica que se deseja atingir. O que interessa agora é perceber como os trabalhadores reelaboram suas questões fundamentais em outra direção em que a formação aponta. Neste sentido,

é preciso que o educador testemunhe aos educados o gosto pela pergunta e o respeito à pergunta. Nos seminários de educação popular, um dos temas introdutórios fundamentais deve ser uma reflexão sobre a pergunta. [...] quando os companheiros riem de uma pergunta, o fazem como uma forma de fugir da situação dramática de não poder perguntar, de não poder externar uma pergunta. [...] É necessário desenvolver uma pedagogia da pergunta, porque o que sempre estamos escutando é uma pedagogia da contestação, da resposta. 
De maneira geral, nós professores, respondemos a perguntas que os alunos não fizeram (FREIRE, 1985, p. 3).

Por isso que, do ponto de vista de um trabalho pedagógico emancipador, não dá para fazer uma transposição imediata da mudança objetiva para subjetiva de forma gradual e controlada justamente pela forma em que se dá o processo. Neste ponto, Freire é assertivo:

Outro equívoco que está presente nesta tensão é o de reduzir a subjetividade a um puro reflexo da objetividade. Então, esta ingenuidade assume que só deve trasnformar-se a objetividade para que, no dia seguinte mude a subjetividade. Não é assim, porque os processos são dialéticos, contraditórios, processuais (FREIRE, 1985, p. 4).

Sobre este elemento, talvez as 'esquerdas' têm esquecido como o papel do 'lugar do outro' no mundo e suas condições objetivas são o ponto de partida para quaisquer processos educativos e de construção de consciência de classe. Assim, Freire nos adverte mais uma vez que:

\begin{abstract}
ninguém chega lá, partindo de lá. Isto é algo que os políticos-educadores e os educadores-políticos esqueceram-se: respeitar a compreensão de mundo, da sociedade, a sabedoria popular, o senso comum que os educandos têm. Em nome da exatidão de julgamento que os educadores, às vezes, julgam possuir, declaram que os grupos populares necessitam desta sabedoria, esquecendo que desconhecemos a percepção que estes grupos têm de sua cotidianidade, a visão que têm da sociedade. [...] temos que pensar a prática para, teoricamente, poder melhorar a prática. Fazer isso demanda uma enorme seriedade, uma grade rigorosidade (e não superficialidade). Exige estudo, criação de uma disciplina séria (FREIRE, 1985, p. 6).
\end{abstract}

Portanto, a imponência e o discurso eloquente parece mais destituir a crítica do que orientar o sujeito à reflexão. Por isso, os trabalhadores que advém de cursos de graduação em saúde, por se utilizarem majoritariamente de métodos pedagógicos tradicionais, sentem-se em um primeiro momento 'incomodados' como método.

É normal esperarem discursos construídos e receitas bem acabadas. No entanto, ao se depararem com esta proposta pedagógica compreendem que o processo é baseado em outra pedagogia. Contudo, mesmo assim, é necessário um equilíbrio entre o ouvirfalar. Assim, Freire pondera: "mas, como escutar implica em falar também, o dever que temos de escutá-los significa o direito que igualmente temos de falar-lhes. escutá-los, no fundo é falar com eles, enquanto simplesmente falar a eles seria uma forma de não ouvilos" (FREIRE, 1985, p. 9).

Ao identificar esses elementos do pensamento freireano para luta social na saúde, compreende-se que há um caminho pedagógico que pode ajudar a elaborar a crítica de forma horizontal, participactiva e dialética. 


\section{Considerações finais}

Ao discorrer sobre a relevância da Sistematização de Experiências como método que ajuda a elaborar uma crítica política aos coletivos que desejam enfatizar esta característica do método, pode-se verificar que o processo de condução do grupo de leitura em conjunto com a proposta de sistematizar a experiência ajudou a adensar a crítica em torno do processo de formação política em questão.

Não é possivel dizer que os caminhos são iguais para os mesmos grupos de trabalhadores nos diferentes momentos de formação política, haja vista que as pessoas são diferentes, seus arcabouços teórico-culturais são distintos e a caminhada para alcançar o elo entre o percorrido pelo trabalhador e o conteúdo trabalhado no curso será sempre singular. No entanto, refletir sobre como construir uma prática pedagógica que se oriente a resgatar esse elo, por meio do pensamento freireano, é essencial para o alcance deste objetivo.

Ao proferir uma reflexão sobre o pensamento freireano a luz do método de sistematização de experiências é possível admitir que a elaboração da crítica se expande ou se consolida, produzindo um processso dialético de reflexão-ação da prática cotidiana e da realidade vivida.

E, no sentido de contribuir com a sistematização de experiência, o método ajuda a elaborar uma crítica política aos coletivos. Explicitou-se por meio do exemplo concreto do 'Coletivo Formação é Política' que a sistematização pode ajudar a refletir a prática de ação formativa a ponto de ser o registro necessário que orienta a transformação desta prática a fim de qualificá-la.

Por fim, para elaborar a crítica entre pensamento freireano, luta social e saúde, a sistematização ajudou a identificar os elementos fundamentais para esse caminho que são: a preocupação genuína do educador com a transformação da sociedade na tentativa de torná-la menos injusta, diminuir cotidianamente a distância entre discurso e prática, considerar que a criticidade que está sendo construída também é sobre o próprio formador, utilizar-se do binômio 'palavras-e-silêncios' pedagógicos, evitar a transposição imediata da mudança objetiva para a subjetiva não se esquecendo do 'lugar do outro' no mundo e suas condições objetivas na hora de identificar os avanços e limites da mudança, e por fim, ao ter como público-alvo trabalhador da saúde nesta proposta de formacão é normal, em um primeiro momento, os trabalhadores se sentirem 'incomodados' como 
método, mas é necessário praticar um equilíbrio entre o ouvir-falar para que os incômodos sejam socializados e abrandados.

Assim, ao sistematizar esta experiência de leitura e reflexão pedagógica, pode-se dizer que se identificou com mais precisão os elementos pedagógicos e que, se exercitados, podem permitir maior adaptação à realidade das virtudes freireanas para o exercício desta prática formadora.

\section{Referências}

ABRASCO. Associação Brasileira de Saúde Coletiva, Rio de Janeiro, 2013. Disponível em: https://www.abrasco.org.br/site/eventos/congresso-brasileiro-de-ciencias-sociais-e-humanasem-saude/a-dificil-construcao-do-dialogo-das-ciencias-sociais-nas-graduacoes-em-saude/1422/. Acesso em: 19 fev. 2019

ALTAMIRA, F., CANARIAS, E. La sistematización de experiencias en el Sur y en el Norte: ¿iguales o diferentes? el proceso del grupo de trabajo de voluntariado de la Congde, Bilbao. Acesso em: 02, mar 2019. Disponível em: http://centroderecursos.alboan.org/ebooks/0000/0712/6_INC_SIS.pdf. 2003.

BOBBIO, N. Política. In: BOBBIO, N. Dicionário de Política. 13. ed. Brasília: Universidade de Brasília, 2016. p. 954-962.

BRAVO, M. I. S. Serviço Social e Reforma Sanitária: lutas sociais e práticas profissionais. 4. ed. São Paulo: Cortez, 2011.

CANSI, L. S. "No canto do mundo do capital": sobre experiência, educação e arte. Revista Educação, Artes e Inclusão, Pelotas, v. 16, n. 1, p. 34-56, jan./mar. 2020.

CARNEIRO, G. Clubes de troca: rompendo o silêncio, construindo outra história. 2. ed. rev. Curitiba: Editora Popular: CEFURIA, 2011.

CARNUT, L. et al. Principais desafios do acolhimento na prática da atenção à saúde bucal: subsídios iniciais para uma crítica. Revista da ABENO, Londrina, v. 17, n. 4, p. 46-62, 2017.

CARNUT, L. et al. Sistematização de experiência como método para elaborar a crítica entre pensamento freireano, luta social e saúde. In: CONGRESSO IBERO-AMERICANO DE INVESTIGAÇÃO QUALITATIVA, 8., 2019, Lisboa. Anais... Lisboa: Ludomedia, 2019, p. 344-353.

CARVALHO, Y. M., CECIM, R. B. Formação e educação em saúde: aprendizados com a saúde coletiva. In: CAMPOS, G. W. S. et al. Tratado de Saúde Coletiva. São Paulo: Editora Hucitec, Rio de Janeiro: Fiocruz, 2006. p. 137-170.

CHAVEZ-TAFUR, J. Aprender com a prática: uma metodologia para sistematização de experiências. Lima, Peru:AS-PTA, 2007.

CRUZ, S. V. 1968: Movimento estudantil e crise na política brasileira. Revista de Sociologia e Política, Curitiba, n. 2, p. 37-55, 1994. 
CURADO, F. F.; SANTOS, A. S.; OLIVEIRA, M. J. Sistematização de experiências agroecológicas no território Semiárido Nordeste II, Bahia. Cadernos de Ciência \& Tecnologia, Brasília, v. 31, n. 2, p. 349-380, maio/ago, 2014.

D’ASCENZI, L., LIMA, L. L. Análise da implementação do método da roda no sistema de saúde de campinas. SP. Sociais e Humanas, Santa Maria, v. 26, n. 1, p. 67-78, jan./abr. 2013.

FERNANDES, F. L.; EDMUNDO, K.; DACACH, S. Sistematização de experiências de prevenção à violência contra jovens. Rio de Janeiro: Observatório de Favelas, 2009.

FERREIRA, A. M. D. et al. Roteiro adaptado de análise de conteúdo - modalidade temática: relato de experiência. J. nurs. health., Pelotas, v. 10, n. 1, p. 1-8, 2020.

FRAGA, A. et al. Uma reflexão sobre a sistematização de aprendizados organizacionais a partir de iniciativas de inclusão produtiva em Unidades de Conservação de Uso Sustentável.

Biodiversidade Brasileira, Brasília, v. 5, n. 1, p. 94-105, 2015.

FREIRE, P. Virtudes do educador. São Paulo: Instituto Paulo Freire, 1985.

FREIRE, P. Não há docência sem discência. In: FREIRE, P. Pedagogia da autonomia: saberes necessários à prática educativa. 25. ed. São Paulo: Paz e Terra, 1996. p. 21-45.

GALARRAGA, A, M. F. Relações pedagógicas e práticas socioambientais: uma prática de sistematização de experiência. 2013.Tese (Doutorado em Educação) - Programa de Pósgraduação em Educação, Universidade do Vale do Rio dos Sinos, Campus São Leopoldo, Porto Alegre, 2013.

GEROMINI, P. R. P. Detecção da violência contra mulher na consulta médica com o uso do instrumento "Conflitos Familiares Difíceis": uma sistematização de experiência. 2019. Dissertação (Mestrado em Saúde da Família) - Faculdade de Medicina, Universidade Estadual Paulista Júlio de Mesquita Filho, Botucatu - São Paulo, 2019.

GOYENECHE, C. E. P.; PLATA, O. F. A.; GARCÍA, P. A. M. Apropiación de dispositivos móviles en educación: una experiencia de sistematización sobre uso pedagógico de TIC en tabletas. Revista interamericana de investigación, educación y pedagogía, Bogotá, v. 13, n. 1, p. 13-30, dic. 2020.

GONZÁLEZ, J. Translating global evidence into local practice: The Latin American experience. Revue internationale d'éducation de Sèvres, Sèvre, v. speciaux, n. 3, p. 1-6, jun. 2019.

HOLLIDAY, O. J. Para sistematizar experiências. 2.ed. revista. - Brasília: MMA, 2006.

HOLLIDAY, O. J. Sistematização de Experiências: Aprender a dialogar com os processos. Lisboa: Ed. CIDAC, 2008.

KUBO, R. R. Metodologias participativas e sistematização de experiências. In: SOGLIO, F.; KUBO, R. R. Agricultura e sustentabilidade. Porto Alegre: Editora UFRGS, 2009. p. 135150.

JINKINGS, I.; DORIA, K. E; CLETO, M. Por que gritamos Golpe? Para entender o impeachment e a crise política no Brasil. São Paulo: Editora Boitempo, 2016.

MARIÁTEGUI, J. C. Sobre a Educação. In: MARIÁTEGUI, J. C. Sete ensaios de interpretação da realidade peruana. São Paulo: Alfa-Ômega, 1975. p. 73-112. 
MARX, K.; ENGELS, F. O manifesto comunista. 5a. reimpressão. São Paulo: Boitempo, 2007.

MOREIRA, G. O. et al. Inclusão social e ações afirmativas no ensino superior no Brasil: para quê? Revista Educação Superior, Campinas, 2017. Disponível em:

https://www.revistaensinosuperior.gr.unicamp.br/artigos/inclusao-social-e-acoes-afirmativasno-ensino-superior-no-brasil-para-queij. Acesso em: 19 fev. 2019.

MOURA, M. R. L. O Grêmio Estudantil na gestão da escola democrática: protagonismo e resiliência ou despolitização das práticas formativas? Revista de Ciências da Educação UNISAL, São Paulo, v. XII, n. 23, p. 273-292, $2^{\circ}$ semestre. 2010.

OLIVEIRA, M. R. et al. Nursing care systematization: perceptions and knowledge of the Brazilian nursing. Rev Bras Enferm, São Paulo, v. 72, n. 6, p. 1547-53, nov./dez. 2019.

PELOSO, R. Trabalho de base: seleção de roteiros selecionados pelo Cepis. São Paulo: Expressão Popular, 2012.

PEREIRA, A. L. F. As tendências pedagógicas e a prática educativa nas ciências da saúde. Cadernos de Saúde Pública, Rio de Janeiro, v. 19, n. 5, p. 1527-1534, 2003.

RODRÍGUEZ, C. S. Una propuesta epistemológica para la sistematización de experiencias generada desde la reflexión sobre la práctica. Revista interamericana de educación, pedagogía y estudios culturales, Colombia, v. 9, n. 2, p. 11-26, jul./dic. 2016.

RODRÍGUEZ-SOSA, J. et al. Systematization of a Training Experience for In-service Teachers through the Use of an Action Research Component. Purposes and Representations, Lima, v. 7, n. 1, p. 107-145, jan./apr. 2019.

SCHWARTZ, G. A. D. A saúde na pós-modernidade. Revista de Direito Sanitário, São Paulo, v. 3, n. 1, p. 29-37, mar. 2002.

SIMON, A. A. Sistematização de processos participativos: o caso de Santa Catarina. Rev. Bras. Agroecologia, Florianópolis, v.2, n.1, p. 1-4, fev. 2007.

TRAGTENBERG, M. Sobre educação, política e sindicalismo. 3. ed. São Paulo: Editora Unesp, 2007.

TRIGOS-CARRILLO, L.; FONSECA, L.; REINOSO, N. Social Impact of a Transformative Service-Learning Experience in a Post-conflict Setting. Front. Psychol., Lausanne, Switzerland, v. 11, n. 47, p. 1-12, jan. 2020.

Recebido em: 02 de fevereiro de 2020.

Aceito em: 02 de abril de 2020 . 